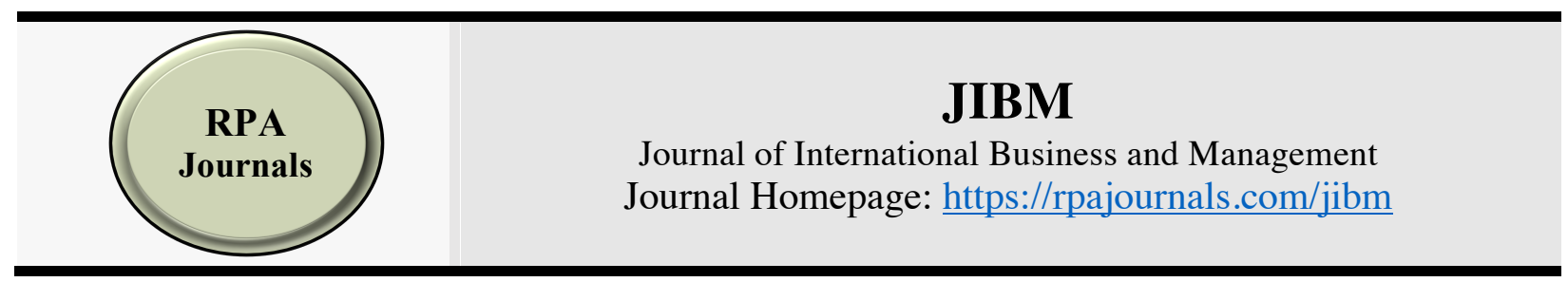

\title{
Performance Predictive Analytics for Operations Management of Shared Services
}

\author{
Hai Wang \\ Sobey School of Business, \\ Saint Mary's University, Canada
}

\begin{abstract}
Shared services have been widely used in many organizations as an alternative to outsourcing. For shared services, common services are standardized and consolidated across multiple organizations to reduce the operational cost and to increase information and knowledge sharing. Two major advantages of shared services over outsourcing are long-term stable cost-saving and knowledge sharing. One important aspect of successful operations management of shared services is to ensure the quality of services delivered by a shared service provider to each individual partner organization. This paper proposes a performance predictive analytics framework for operations management of shared services. The paper presents a case study to demonstrate the usefulness and effectiveness of this framework.
\end{abstract}

Keywords: Shared Services; Business Analytics; Performance Prediction; Key Performance Indicators; Queuing Network Model

*Corresponding author: Hai Wang; Email: hwang@smu.ca

DOI: https://doi.org/10.37227/JIBM-2020-03-18

\section{Introduction}

The cloud computing technology has accelerated shared services in private enterprises (Leavell, 2006; Rolia, Cherkasova, Arlitt, \& Machiraju, 2006), the healthcare industry (Topacan, Basoglu, \& Daim 2010; McDowell, 2011), and the government sector (Janssen \& Joha, 2006; Williams, 2006; Almutairi, 2008). Shared services refer to the standardization and consolidation of common functions across multiple organizations to reduce information process duplication and increase information and knowledge sharing. The crossorganizational dimension of shared services makes up distinctive characteristics in contrast to other contemporary management practices. Many organizations have discovered that implementing shared services requires tremendous organizational support to make shared services workable for their specific situations (Rison, 2005; Wolf \& Mujtaba, 2011).

Services for common functions in individual organizations can be shared to reduce business process duplication and increase knowledge sharing through IT-supported standardization and consolidation of these service processes (Davenport \& Short, 1990; Spohrer \& Kwan, 2009; Targowski, 2009). Generally, accounting and financial management, human resources management, acquisition transactions, and customer 
relationship management are the designated lines of business processes for shared services. Shared services are often mistakenly considered to be outsourcing. In fact, the differences between shared services and outsourcing are significant in many aspects (Sako, 2010). Overall, shared services bring in long-term stable competitive advantages, while outsourcing involves much uncertainty (King, 2006). In terms of general organizational structure, the shared services center, the provider of shared services for the partner organizations, is formed and governed by the partners, while the relation between the service provider and the outsourced firm in outsourcing is bilateral. The major strategies behind shared services are long-term cost-saving and knowledge sharing beyond sourcing business processes for the short term. Effective shared services are achieved by standardization of processes to reduce process duplication across the entire shared services network. Table 1 summarizes a comparison of shared services and outsourcing.

Table 1. Shared services vs. outsourcing

\begin{tabular}{|l|l|l|}
\hline \multicolumn{1}{|c|}{ Managerial Aspects } & \multicolumn{1}{|c|}{ Shared Services } & \multicolumn{1}{c|}{ Outsourcing } \\
\hline General organizational structure & $\begin{array}{l}\text { Networking with shared } \\
\text { services center }\end{array}$ & $\begin{array}{l}\text { Bilateral relation with } \\
\text { the outsourced firm }\end{array}$ \\
\hline Strategies & $\begin{array}{l}\text { Long-term stable cost saving } \\
\text { and knowledge sharing }\end{array}$ & $\begin{array}{l}\text { Cost saving for the } \\
\text { short term }\end{array}$ \\
\hline Risk sharing among partners & Yes & No \\
\hline $\begin{array}{l}\text { Coordination of process re-engineering } \\
\text { and standardization of processes }\end{array}$ & Yes & No \\
\hline Reduce process duplication & Yes & No \\
\hline Knowledge sharing among partners & Yes & No \\
\hline Central control (e.g., policies) & Yes & No \\
\hline Leverage of information technology & Yes & No \\
\hline IT human resource changes & Re-deployment and training & Staff reduce \\
\hline
\end{tabular}

The importance of organizational support to better fit the changing environment of competition is a familiar theme in the organizational theory field (Wang, 1997). Given the unique characteristics of shared services, research (Wang \& Wang, 2007) has suggested that strategy of shared services management, collaborative partnership network design, optimal service process design, and policy and regulation design are the major aspects of organizational support for shared services. Other aspects of organizational support, such as leadership, control span, and culture could be important for the success of shared services in general, but are secondary to these major aspects.

There has been an abundant research literature on organizational management of shared services. However, few papers on operations management of shared services can be found. This paper proposes a performance predictive analytics framework to measure, monitor, predict and control the quality of shared services. 
The remainder of this paper is organized as follows. Section 2 presents related work of shared services. Section 3 describes the proposed performance predictive analytics framework for operations management of shared services. Section 4 presents a case study to demonstrate the usefulness and effectiveness of the proposed framework. Finally, Section 5 summarizes the conclusions.

\section{Related Work}

\section{Strategies of Shared Services}

In general, two types of strategic opportunities can be counted on as a result of shared services. One is cost-saving through business process reengineering (Davenport \& Short, 1990). By sharing common non-core business functions such as accounting, financial transactions, human resource management, and customer services would dramatically improve business performance of all shared services partner organizations. Another promising advantage of shared services is information and knowledge sharing. For instance, shared distribution services allow the partners to share dependable marketing information (Krempel, 2000; Gupta \& Lawsirirat, 2013). Goals related to shared services include

(1) cost-saving of business processes and improve services in the long run;

(2) building a long-term strategic alliances with other organizations to share information and knowledge; and

(3) establishing leadership through a focus on core functions.

There are two methods that can be used to define the strategy for the organization (Galbraith, 1977; 1982; Nadler \& Tushman, 1988) that are relevant to shared services management. One is a top-down value chain analysis (Porter \& Millar, 1985). Value chain analysis provides a framework for information technology planning and strategy formulation. This framework is appropriate for shared services since it is useful for assessing the values of shared services. In performing value chain analysis, an organization can define its strategic direction by pursuing shared services such as lowering transaction costs, providing more services to customers, and share knowledge with the shared services partners. The second method is bottom-up non-core function analysis to identify potential benefit and risk of sharing these non-core functions with other organizations.

\section{Strategic Partnership in Shared Services}

Research (Kakabadse \& Kakabadse, 2000) has indicated that successful implementation of shared services requires new organizational forms of sourced service consortia organizations based on organizational analysis in understanding contracting, markets and the nature of cooperation. Shared services drive the partner organizations to form a network with the nucleus of shared services center. A shared services center facilitates the partner organizations and provides shared services and knowledge. Each individual partner organization is a stockholder of the center and acts as part of governance of the center. A shared services network is a virtual organization that actualizes value-adding, resource sharing, and risk-sharing partnerships.

Organizations tend to perform only those functions that they do best and arranging for other non-core functions to be performed by other companies. The resulting collection of independent, mostly single-function business units forms a network organization (Miles \& Snow, 1986; Mohrman \& Cummings, 1989; Liu, Zhang, \& Meng, 2011). The rationale behind shared services is that organizations tend to do fewer things better and with less, to 
be strong competitors. Organizations perform only those core functions for which they have expert skills, and share with alliance organizations those non-core services that can be performed more economically while are governed by the shared services network.

Shared services create sophisticated networks that have all characteristics of interorganizational networks as well as intra-organizational networks. The independent partner organizations of the shared services form an inter-organizational network. The network is governed by a board which is elected by the partner organizations. As the day-to-day operations of the shared services are coordinated by the shared services center, and the shared services center is in turn governed by the partner organizations, the center and its governance organizations assemble intra-organizational networks.

Partners and shared services center are the fundamental components for supporting a shared services network. Although little research on hidden costs of shared services network construction has been done, it is certain that partner selection and shared services center formation are demanding and costly.

Shared services partners are long-term business alliances. A shared services partner must meet four criteria. First, the partner organization provides similar non-core functions that can be shared. Second, the partner can perceive the potential benefit of the shared services. Third, the partner is willing and capable to take the risk involved in the development of the shared services. Fourth, the partner possesses knowledge for the implementation of the shared services. In the organizational theory community, there is growing agreement about the basic characteristics of the network organization (Snow, Miles, \& Coleman 1992; Mowshowitz, 1997). To understand fully how networks are designed and operated, and where their applications lie, one must study organizational support in the shared services context.

\section{Business Process Optimization in Shared Services}

Shared services would optimize the operational business processes at the shared services network level. Few research reports can be found in the literature on management of the environment of shared services; yet, workflow management (Ferreira \& Ferreira, 2005) is considered a technique for organizations to manage the new technological environment of shared services. Workflow management can be used to re-examine shared services related business process and the relationships between business units. The flow of shared services determines the shared services structure, eliminating the duplicated processes for the network. Workflow management permits the partner organizations to share the understanding of the shared services, and to support the shared processes to meet the shared services strategies.

According to (Mintzberg, 1979; Trist, 1982; Pasmore, 1988; Mackenzie, 1991; Pasmore \& Mlot, 1994), every organized human activity gives rise to two fundamental and opposing requirements: the division of labor into various tasks to be performed and the coordination of these tasks to accomplish the activity. The two fundamental requirements can be fulfilled by optimal service process design in shared services. Optimal service process design includes optimal workflow design and optimal human resource design.

\section{(1) Shared services require IT-enabled business process re-design}

Research (Ulbrich, 2006) has revealed the synergy relationship between business process reengineering and shared services, and has compellingly argued that business process reengineering is inevitable when implementing shared services. In fact, the implementation process of shared services is a transformation process of the structures of the involved 
organizations including the business processes and workflows (Ulbrich, 2010). Optimal workflow design for shared services involves elimination of valueless business processes, negotiation for unique business processes, standardize the service processes, and knowledge sharing of business process reengineering (Mora, Raisinghani, O'Connor, \& Gelman, 2009; Zandi \& Tavana, 2011). There are three levels of optimal workflow design. At the individual partner level, the service requirements are modeled in workflows based on maximum value-adding. At the shared services network level, duplicated business processes are eliminated. At the shared services center level, all required workflows are optimized so that the services are provided at lowest costs (Pires, van Oostrum, \& Wijnhoven, 2010; Tsafarakis, Delias, \& Matsatsinis, 2013).

(2) Shared services require re-design of human resource structures

As shared services involve substantial changes of business processes and division of labor, re-design of human resource structures becomes more important than ever in the engaged organizations of shared services (Tsai \& Yen, 2008). Reduction-in-force can be a strategic consideration or an outcome of shared services (Gandolfi, 2010). New training programs and new rewarding systems are created in the organizations for the implementation of business process reengineering (Ali, 2012). An appropriate human resource base is particularly crucial for the shared services center where people are knowledgeable and capable to deliver the shared services (Borman, 2010). Hiring new skilled people, training the current employees to fit the new environment, and potential downsizing as a result of shared services are all new challenges for the organizations engaged in shared services.

\section{New Policies and Regulation in Shared Services}

Shared services create a special environment for partner organizations. The biggest issue in shared services is cost distribution among the partner organizations (Baron, Beyer, \& Bitran, 2005). Mutual agreement on the cost distribution formula must be established for the shared services network. The bottom line for shared services is that every partner organization must receive a fair share of cost-saving.

Shared services create two new sets of policy and regulation issues in addition to cost distribution. One is related to the funding and governance of the shared services center. The other is related to the rules of access of shared services. It is extremely important to realize that any bylaw of shared services does not guarantee the success of shared services, but the success of shared services must be backed up by a bylaw.

Organizational redesign process defines the course of action and requires varying amounts of improvisation (Weick, 1977). New shared services introduce new policies and regulation for the partner organizations in the form of bylaws of the service network. The bylaws specify the rights and responsibilities of the partner organizations for the shared services. Generally, shared services create three categories of new policies and regulations.

\section{(1) Governance of the shared services network and center}

As the shared services engage multiple organizations, new governance of the shared services network is the key organizational change for the partners to implement the administrative elements of the shared services (Kamal, 2012; Ulbrich, 2010). The configuration of shared services collaborative network is the summation of service operation network structure, negotiation network structure, and value-chain network structure (Lindvall \& Iveroth, 2011). The shared services center is the coordinator of the collaborative network and represents the common interest of all partner organizations (Niehaves \& Krause, 2010). The responsibility 
of a shared services center is to maintain and enhance the shared services and to develop cohesion among the partners of the share services (Minnaar 2013). The governance board of the shared services network exercises the charters of the board, acquires financial capital for the center, hires the general manager of the center, and monitors the operations of the shared services (Amiruddin, 2013).

(2) Cost distributions of the shared services

The governance of shared services network may leave many issues to be filled by negotiations among various actors with different roles, goals, and action space (Ask, Hatakka, \& Gronlund, 2008). The scheme that allocates the cost and reserves the shared resources is the top negotiation item among the partners (James, 2006). The shared services network must have a mutually agreed and unambiguous cost distribution scheme to reduce the risk level of shared services and to increase the ability to implement other policies (Schultze, 2011).

(3) Shared services access authorities and ethical codes

Information technology is commonly applied to the implementation of shared services, and information access authorization and security have become a strategic consideration of shared services (Maitner, 2011; Jaffar \& Weistroffer, 2012). During the implementation, shared services often involve ethics issues in the intellectual property aspects (Gupta, 2008). More importantly, while playing the dual roles in their own organizations and the shared services network, managers and shared services staffs ought to deal with conflict interest, and their conduct has important implications for the healthy shared services partnership (Zeemering, 2008; Brandau \& Hoffjan, 2010). Hence, stable and reliable shared services are always regulated by service access authorization rules and ethical codes related to the shared services.

\section{Performance Predictive Analytics for Shared Services}

Business analytics refers to the practice for continuous iterative exploration and investigation of relevant business data to improve an organization's performance. There are three popular types of business analytics, descriptive analytics, predictive analytics and prescriptive analytics. Descriptive analytics involves utilizing quantitative, statistical and data visualization techniques to gain new business insights. Predictive analytics exploits relevant data to make well-defined predictions supported by data. Prescriptive analytics applies optimization techniques, in addition to predictive analytics, to recommending plausible business decision options.

We propose a performance predictive analytics framework to measure, monitor, predict and control the quality of shared services. The main goal of this framework is to achieve efficient operations management and quality assurance of shared services. As illustrated in Figure 1, the framework consists of the following five processes:

1) Designing a set of the key performance indicators (KPIs) for evaluating the success of shared services,

2) Real-time or nearly real-time data collection for KPIs.

3) Continuous monitoring and reporting of the KPIs,

4) Prediction of the KPIs in short-term using prediction techniques,

5) Long-term KPI-based management planning of the operations of shared services. 


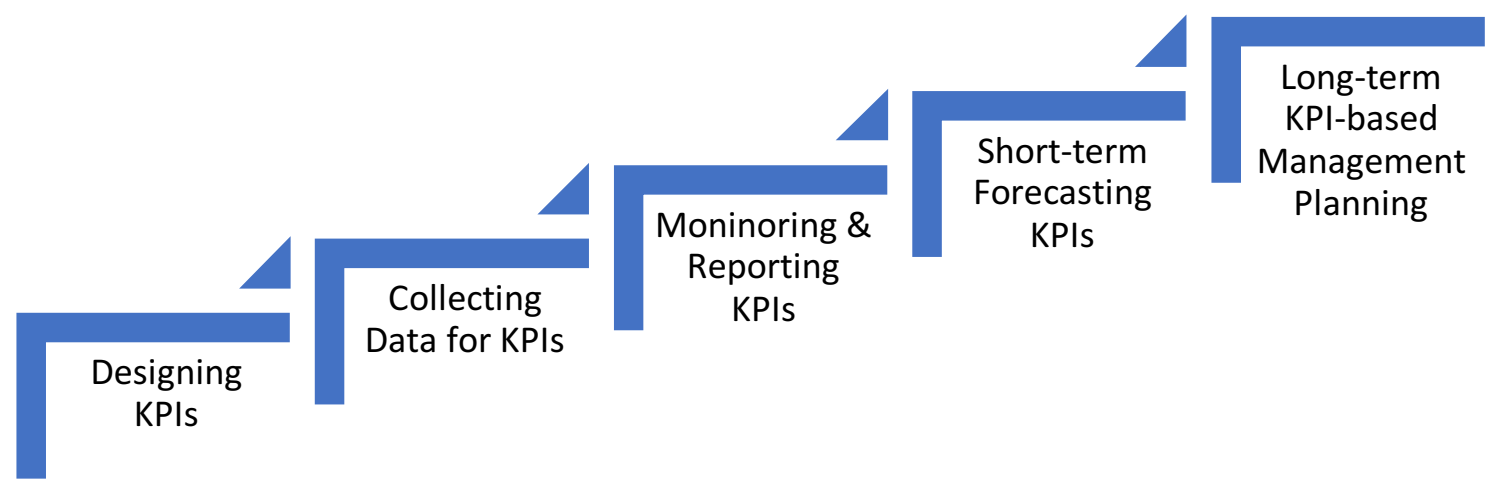

Figure 1. The processes of the performance predictive analytics framework

The design of KPIs depends on the types of delivered services. Different types of shared services have different KPIs. Examples of the KPIs include

- Utilization of a particular equipment, which is defined as the percentage of the time that the equipment was actually used for completing service requests.

- Throughput of the shared services center, which is defined as the average number of service requests processed by the shared services center within a specific unit of time.

- Average turnover time of service requests within a time period, where the turnover time is defined as the time from the submission of a service request to the completion of the service request.

- Maximum turnover time of service requests within a time period.

- Total number of service requests completed within a time period.

- Total operational cost of the shared service center within a time period.

Moreover, service requests from all partner organizations can be subdivided into different classes. Different classes correspond to different types of services with different characteristics. Service requests from different partner organizations could be in different classes. Service requests from the same partner organization could be in different classes as well, such as the high-priority requests and the low-priority requests. Specific KPIs can be designed for a specific class of service requests. For example, a KPI could be defined as the maximum turnover time of a specific class of service requests within a time period. including

Furthermore, many prediction techniques can be integrated into this framework,

1. traditional time-series forecasting techniques, such as the autoregressive integrated moving average method (ARIMA);

2. machine learning techniques, such as the deep neural networks; and

3. queuing network models.

When the KPIs follow linear functions or simple nonlinear functions, traditional time-series forecasting techniques and/or machine learning techniques are able to yield accurate predictions. When there are queues (i.e., waiting lines) for specific resources within the shared service provider, the KPIs are typically complex nonlinear functions, and it is generally believed that queuing network models are capable of resulting in more accurate prediction of KPIs than other prediction techniques (Wang \& Sevcik, 2000; Wang et al., 2008). A queuing network model is a network of queues, where certain KPIs can be 
computed using algorithms (Wang \& Sevcik, 2000; Wang et al., 2008). For example, the input of a queuing network model is the average time for an employee to complete a certain class of service requests, and the output of the queuing network is the average turnover time of this class of service requests by taking into account the waiting time in the queues. As shown in Figure 2, a KPI associated with queuing can be decomposed into two component: (1) a pre-queuing component that can be predicted using traditional time-series or machine learning techniques, and may be used as the input of the queuing network model; and (2) a queuing component that reflects the queuing effect on the KPI and can be computed as the output of the queuing network model.

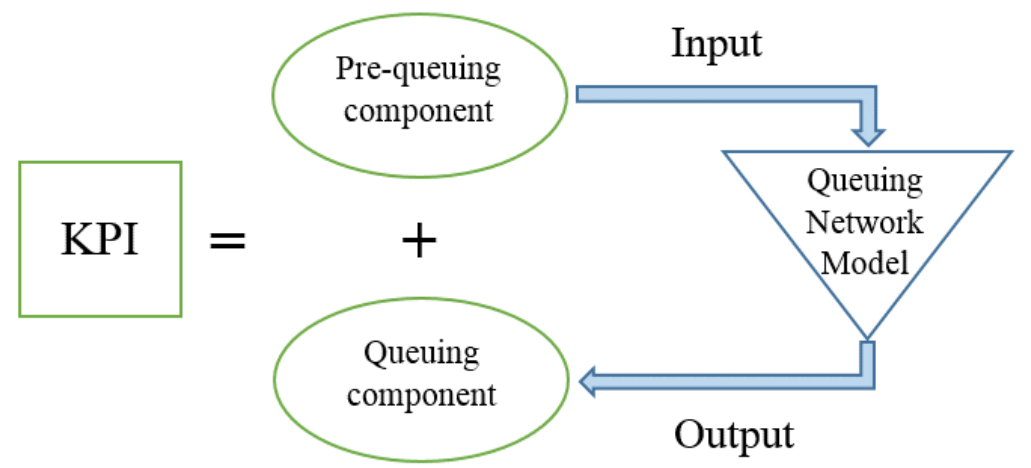

Figure 2. KPI prediction with a queuing network model

\section{A CASE STUDY}

The usefulness and effectiveness of the aforementioned performance predictive analytics framework is demonstrated by the following case study. Eleven hospitals in an Asia-Pacific country established a shared services center to provide IT supporting services. Clouding computing technology was used to store data. A call center was set up to handle IT service requests from hospital staffs.

Service requests from a hospital were subdivided into 8 classes based on the nature of the services. Hence, there are 88 classes of service requests in total for all 11 hospitals. For each class of service requests, the KPIs included

- Throughput of this class of service requests within a day.

- Utilization of the shared services center for this class of service requests within a day.

- Daily average number of this class of service requests,

- Daily maximum number of this class of service requests,

- Daily maximum turnover time of this class of service requests.

For the call center, the KPIs included

- Throughput of the call center within a day, which is defined as the average of the throughputs of all 88 classes.

- Utilization of the call center within a day, which is defined as the sum of the utilizations for all 88 classes.

- Maximum turnover time of all service requests within a day.

A queuing network model was constructed for the call center, and a weekly seasonal ARIMA model

$$
\widehat{Y}_{t}=\mu+Y_{t-7}+w_{1}\left(Y_{t-1}-Y_{t-8}\right)-c_{1} e_{t-1}-k_{1} e_{t-7}+c_{1} k_{1} e_{t-8}
$$


was constructed to predict various KPIs as well as input of the queuing network model, where $\hat{Y}_{t}$ is the predicted value for the time period $t, Y_{t-i}$ is the actual value measured for the time period $t-i, i=1,7,8$, and the constants $\mu, w_{1}, c_{1}, k_{1}, e_{t-i}, i=1,7,8$, are the ARIMA model parameters to be estimated from the historical data.

Raw data were collected over a 5-month period to validate this model. There were 28,147 service requests in total over the five months. The time-series cross-validation procedure was used to calculate the overall accuracy of the model. As shown in Figure 1, there were a series of test sets, each consisting a single prediction. The overall prediction accuracy is computed by averaging all test sets.

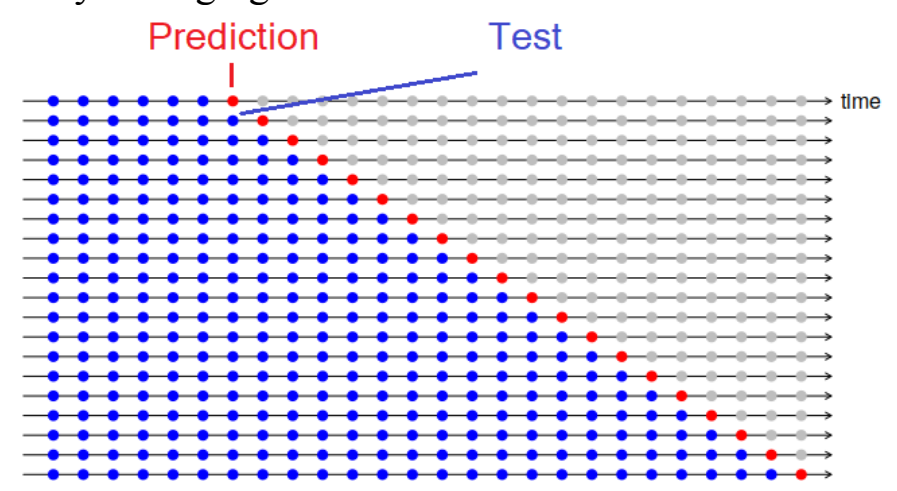

Figure 3. The time-series cross-validation procedure

Five accuracy measurements of the predictions were used:

1) The correlation coefficient

2) The normalized mean bias error

$$
r=\frac{\sum_{i=1}^{n}\left(Y_{i}-\bar{Y}\right)\left(\widehat{Y}_{l}-\bar{Y}_{l}\right)}{\sqrt{\sum_{i=1}^{n}\left(Y_{i}-\bar{Y}\right)^{2}} \sqrt{\sum_{i=1}^{n}\left(\hat{Y}_{i}-\bar{Y}\right)^{2}}}
$$

$$
n M B E=\frac{1}{N} \sum_{i=1}^{n} \frac{\widehat{Y}_{l}-Y_{i}}{\bar{Y}} \times 100 \%
$$

3) The normalized mean absolute error

$$
n M A E=\frac{1}{N} \sum_{i=1}^{n} \frac{\left|\widehat{Y}_{l}-Y_{i}\right|}{\bar{Y}} \times 100 \%
$$

4) The normalized root mean square error

5) The mean absolute percentage error

$$
n R M S E=\frac{\sqrt{\frac{1}{N} \sum_{i=1}^{N}\left(\hat{Y}_{i}-Y_{i}\right)^{2}}}{\bar{Y}} \times 100 \%
$$

$$
M A P E=\frac{1}{N} \sum_{i=1}^{n} \frac{\left|\widehat{Y}_{l}-Y_{i}\right|}{Y_{i}} \times 100 \%
$$

where $\hat{Y}_{i}$ is the predicted value and $Y_{i}$ is the actual value measured at the time $i$. Table 2 shows the prediction accuracy when the following KPIs were predicted and validated.

- $X=$ Throughput of the call center for the next day,

- $\mathrm{U}=$ Utilization of the call center for the next day, 
- $\mathrm{R}=$ Maximum turnover time of all service requests for the next day.

When the values of $X, U$ and $R$ are known, the number of employees needed to work at the call center for the next day can be easily determined to ensure the quality of the services.

Table 2. The prediction accuracy results

\begin{tabular}{|c|c|r|r|r|r|}
\hline $\mathrm{KPIs}$ & \multicolumn{1}{|c|}{$r$} & $n M B E(\%)$ & $n M A E(\%)$ & $n R M S E(\%)$ & $M A P E(\%)$ \\
\hline$X$ & 0.91 & -2.46 & 4.03 & 4.98 & 3.91 \\
\hline$U$ & 0.90 & 3.17 & 4.28 & 5.79 & 4.52 \\
\hline$R$ & 0.94 & 2.01 & 5.57 & 5.01 & 5.23 \\
\hline
\end{tabular}

The performance predictive analytics framework has been adopted by the shared service center to predict the values of the KPIs and then to determine number of employees required at the call center for the next day. The shared service center has been successfully operational for more than two years.

\section{Conclusion}

In this paper, we have proposed a performance predictive analytics framework for operations management of shared services. The proposed performance predictive analytics framework utilizes a set of key performance indicators and the queuing network model. We have demonstrated the usefulness and effectiveness of the proposed framework through a case study for a call center of a shared services provider. In the case study, we have computed five different accuracy measurements of predictions on three key performance indicators that have been widely used for call centers. It is our conclusion that the proposed framework is capable of achieving efficient operations management of shared services.

Traditionally, there are always some limitations in the papers while one limitation of the paper is that the case study only involves a call center. Different types of shared services centers may employ different key performance indicators. In the future, we plan to collect more data from different shared services centers. We will further examine the effectiveness and robustness of the proposed framework for a variety of different shared service centers.

\section{Acknowledgment}

This paper was presented at the Applied Research International Conferences on Business \& Management (ARICBM), 2019, United Kingdom (UK).

\section{References}

Ali, M. H. (2012). An analysis of raining and rewards factors on the reengineering process as implemented in Telcomm. The Journal of Human Resource and Adult Learning, $8(1), 169-174$.

Almutairi, H. (2008). Information system usage and national culture: Evidence from the public service sector. International Journal of Society Systems Science, 1(2), 151175. 
Amiruddin, R. (2013). Mitigating risks in a shared service relationship: The case of a Malaysian bank. Qualitative Research in Accounting and Management, 10(1), 7893.

Ask, A., Hatakka, M., \& Gronlund, A. (2008). The Orebro city citizen-oriented egovernment strategy. International Journal of Electronic Government Research, 4(4), 69-88.

Baron, O., Beyer, D., \& Bitran, G. R. (2005). Pricing of shared computer services. Journal of Revenue and Pricing Management, 4(1), 54-65.

Borman, M. (2010). Characteristics of a successful shared services centre in the Australian public sector. Transforming Government: People, Process and Policy, 4(3), 220-231.

Brandau, M., \& Hoffjan, A. H. (2010). Exploring the involvement of management accounting in strategic decisions and control: The case of offshoring. Journal of Accounting \& Organizational Change, 6(1), 72-95.

Davenport, T. H., \& Short, J. (1990). The new industrial engineering. Sloan Management Review, 31(4), 11-27.

Ferreira, D. M. R., \& Ferreira, J. J. P. (2005). Towards a workflow-based integration architecture for business networking. Business Process Management Journal, 11(5), 517-531.

Gandolfi, F. (2010). Reduction-in-force (RIF) - New developments and a brief historical analysis of a business strategy. Journal of Management and Organization, 16(5), 727-743.

Gupta, A. (2008). Evolving relationship between law, offshoring of professional services, intellectual property, and international organizations. Information Resources Management Journal, 21(2), 103-126.

Gupta, A., \& Lawsirirat, C. (2013). Developing service operations strategy for optimal delivery of long-term service agreements using an integrated risk framework. International Journal of Information Systems in the Service Sector, 5(1), 33-67.

James, W. (2006). A processual view of institutional change of the budget process within an Australian government-owned electricity corporation. The International Journal of Public Sector Management, 19(1), 5-39.

Janssen, M., \& Joha, A. (2006). Motives for establishing shared service centers in public administrations. International Journal of Information Management, 26(2), 102-112.

Kakabadse, A., \& Kakabadse, N. (2000). Sourcing: New face to economies of scale and the emergence of new organizational forms. Knowledge and Process Management, 7(2), 107-118.

Kamal, M. M. (2012). Shared services: lessons from private sector for public sector domain. Journal of Enterprise Information Management, 25(5), 431-440.

King, D. R. (2006). Implications of uncertainty on firm outsourcing decisions. Human Systems Management, 25(2), 115-124.

Krempel, M. (2000). Restructuring business for the new Europe. Strategic Direction, 16(5), $13-15$.

Leavell, H. (2006). International working capital management. The Business Review, 5(1), 233-239. 
Lindvall, J., \& Iveroth, E. (2011). Creating a global network of shared service centres for accounting. Journal of Accounting \& Organizational Change, 7(3), 278-305.

Liu, S., Zhang, Y., \& Meng, X. (2011). Towards high maturity in SaaS applications based on virtualization: Methods and case study. International Journal of Information Systems in the Service Sector, 3(4), 39-53.

Maitner, R. E. Jr. (2011). Moving to the cloud: is federal financial management fair game? The Journal of Government Financial Management, 60(3), 52-57.

McDowell, J. (2011). Shared services centers can drive significant savings. Healthcare Financial Management, 65(6), 118-124.

Minnaar, R. A. (2013). Shared service centres and management control structure change. Journal of Accounting \& Organizational Change, 9(1), 74-98.

Mora, M., Raisinghani, M. S., O'Connor, R., \& Gelman, O. (2009). Toward an integrated conceptualization of the service and service system concepts: A systems approach. International Journal of Information Systems in the Service Sector, 1(2), 36-57.

Niehaves, B., \& Krause, A. (2010). Shared service strategies in local government - a multiple case study exploration. Transforming Government: People, Process and Policy, 4(3), 266-279.

Pires, L. F., van Oostrum, A., \& Wijnhoven, F. (2010). Service registry design: An information service approach. International Journal of Information Systems in the Service Sector, 2(4), 1-21.

Rison, R. P. (2005). How to reduce the cost of HR and continue to provide value. Human Resource Planning, 28(1), 14-17.

Rolia, J., Cherkasova, L., Arlitt, M., \& Machiraju, V. (2006). Supporting application quality of service in shared resource pools. Communications of the ACM, 49(3), 55-60.

Sako, M. (2010). Technology strategy and management outsourcing versus shared services. Communications of the ACM, 53(7), 27-33.

Schultze, U. (2011). Finding the process edge: ITIL at Celanese. Journal of Information Technology Teaching Cases, 1(1), 22-39.

Spohrer, J., \& Kwan, S. K. (2009). Service science, management, engineering, and design (SSMED): An emerging discipline - outline \& references. International Journal of Information Systems in the Service Sector, 1(3), 1-31.

Targowski, A. (2009). The architecture of service systems as the framework for the definition of service science scope. International Journal of Information Systems in the Service Sector, 1(1), 54-77.

Topacan, U., Basoglu, A. N., \& Daim, T. U. (2010). Exploring the adoption of technology driven services in the healthcare industry. International Journal of Information Systems in the Service Sector, 2(1), 71-93.

Tsafarakis, S., Delias, P., \& Matsatsinis, N. (2013). A Service-oriented approach for the optimal product/service design business process. International Journal of Information Systems in the Service Sector, 5(1), 2013, 68-81.

Ulbrich, F. (2006). Improving shared service implementation: Adopting lessons from the BPR movement. Business Process Management Journal, 12(2), 191-205. 
Ulbrich, F. (2010). Adopting shared services in a public-sector organization. Transforming Government: People, Process and Policy, 4(3), 249-265.

Wang, H., \& Sevcik, K. C. (2000). Experiments with improved approximate mean value analysis algorithms. Performance Evaluation, 39(1-4), 189-206.

Wang, H., Sevcik, K. C., Serazzi, G., \& Wang, S. (2008). The general form linearizer algorithms: A new family of approximate mean value analysis algorithms. Performance Evaluation, 65(2), 129-151.

Wang, S. (1997). Impact of information technology on organization. Human Systems Management, 16(2), 83-90.

Wang, S., \& Wang, H. (2007). Shared services beyond sourcing the back offices: Organizational design. Human Systems Management, 26(4), 281-290.

Williams, C. A. (2006). Advancing federal financial management. The Journal of Government Financial Management, 2006, 55(4), 52-57.

Wolf, F., \& Mujtaba, B. G. (2011). Sustainability in service operations. International Journal of Information Systems in the Service Sector, 3(1), 1-20.

Zandi, F., \& Tavana, M. (2011). A strategic benchmarking process for identifying the best practice collaborative electronic government architecture. International Journal of Information Systems in the Service Sector, 3(2), 32-56.

Zeemering, E. S. (2008). Governing interlocal cooperation: City council interests and the implications for public management. Public Administration Review, 68(4), 731741,598-599. 